h

UNCLASSIFIED

\title{
HANFORD STUDIES
}

\section{OF EGCR COMBUSTION CHARACTERISTICS}

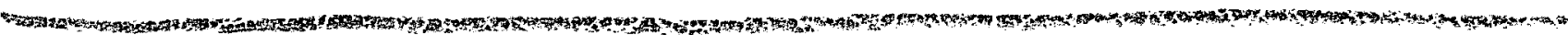

D. R. DE HALAS

R. E. DAHL

J. L. JACKSON

OCTOBER 10, 1961

HANFORD ATOMIC PRODUCTS OPERATION

RICHLAND. WASHINGTON

\section{GENERAL ELECTRIC}

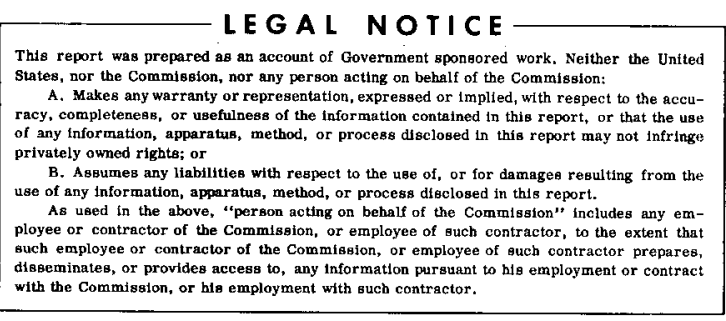




\section{DISCLAIMER}

This report was prepared as an account of work sponsored by an agency of the United States Government. Neither the United States Government nor any agency Thereof, nor any of their employees, makes any warranty, express or implied, or assumes any legal liability or responsibility for the accuracy, completeness, or usefulness of any information, apparatus, product, or process disclosed, or represents that its use would not infringe privately owned rights. Reference herein to any specific commercial product, process, or service by trade name, trademark, manufacturer, or otherwise does not necessarily constitute or imply its endorsement, recommendation, or favoring by the United States Government or any agency thereof. The views and opinions of authors expressed herein do not necessarily state or reflect those of the United States Government or any agency thereof. 


\section{DISCLAIMER}

Portions of this document may be illegible in electronic image products. Images are produced from the best available original document. 
SUMMARY REPORT

HANFORD STUDIES OF EGCR COMBUSTION CHARACTERISTICS

by

D. R. de Halas, R. E. Dahl, J. L. Jackson

October 10, 1961

Nonmetallic Materials Development Operation

Hanford Laboratories Operation

General Electric Company

Work performed under Contract No. AT(45-1)-1350

between the Atomic Energy Commission and

General Electric Company 
FW Albaugh

JA Ayres

WF Banks - AC

RW Benoliel

FD Bush - KE

FI Carlsen - ORNL

RE Dahl

DR de Halas (25)

RL Dilion

DH Gurinsky/DG Schweitzer - BNL

IA Hartcorn

JL Jackson

JO Kolb - ORNL

WJ Larkin - ORO (35)
$\mathrm{FE}$ Nightingale

WD Manly - ORNL

RA Meyer - GA

JM Musser - HOO

RE Olson

RE Pahler - DRD, Wash.

JW Riches

JM Simmons - DRD, Wash.

WR Voigt - DRD, Wash.

PL Walker, Jr. - Penn State

FW Woodfield

300 Files

Record Center

Extra- (10)

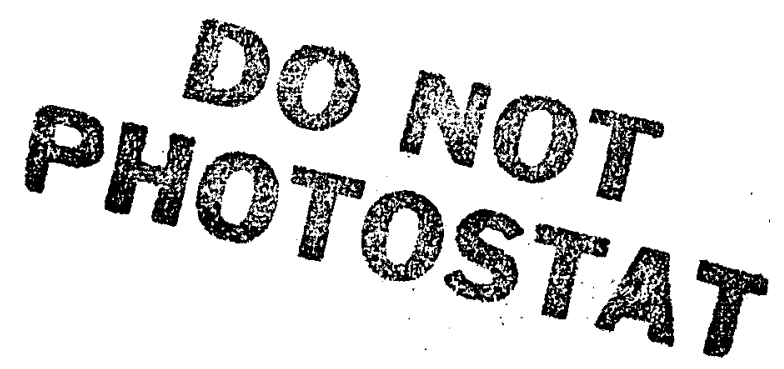


UNCLASSIFIED

HW-71296

SUMMARY REPORT

HANFORD STUDIES OF EGCR COMBUSTION CHARACTERISTICS

\section{INTRODUCTION}

The reaction of oxygen with graphite is exothermic. If, due to some accident, massive amounts of air were drawn into contact with hot moderator graphite in the EGCR, it is conceivable that the heat generated from the oxidation, added to the after-heat of the reactor, might exceed the cooling capabilities of a damaged coolant system. In this event, the temperature of the moderator would continue to rise even though the reactor was shut down. Depending on circumstances, the rate of temperature rise might be quite slow, giving ample time to correct the situation, or might be very rapid.

The exact conaitions under which self-sustained combustion can occur, i.e., When the heat generated equals or exceeds the heat removed by the coolant, depends strongly on the geometry of the moderator system, the initial heat distribution, and the coolant flow. The geometry determines the amount of graphite which is exposed to oxygen and can be involved in the combustion process. The consideration of geometry is complicated by the fact that not only the surface of the graphite oxidizes, but, because of the porous nature of graphite, the oxidation extends to some depth below the surface. The temperature distribution of the reactor determines which regions of graphite are capable of undergoing self-sustained combustion. The temperature distribution includes considerations of both coolant and graphite temperature as well as the rate of heat decay after shutdown. The coolant flow controls the rate at which heat can be removed from the system and at the same time, if there is air mixed with the coolant, determines the rate of access of oxygen to the hot graphite surfaces.

Aside from the system variables just mentioned, there are other significant factors which affect the rate at which graphite will oxidize. These are: the type of graphite, that is structure and impurity level in the graphite; the presence of impurities which have been deposited on the graphite; the irradiation history of the graphite; the amount of prior oxidation which the graphite has undergone; the intensity of gamma radiation; the presence of moisture; and the partial pressure of oxygen in the coolant.

Because of the large number of interrelated variables which affect the possibility of establishing a self-sustained combustion condition within the reactor, the Hanford studies to evaluate the problem have been conducted in several parts. In the first phase of the work, the temperature, geometry and flow conditions which exist in the EGCR have been duplicated as closely as possible in an engineering scale mock-up. This mockmup is designated. 
the "EGCR Burning Rig". Other variables which could not be incorporated readily in the Burning Rig tests, such as the effect of gamma radiation, have been investigated in separate laboratory experiments. Results of the Burning Rig tests have been used along with appropriate correction factors devised from the laboratory studies as basis for predicting the combustion characteristics of the EGCR. The final prediction as to whether selfosustained combustion can exist in EGCR is made on an electronic computer; the computer work has been done at Allis-Chalmers and at Oak Ridge National Laboratory. The accuracy of the computer code has been checked by testing the ability of the machine computation to predict the combustion characteristics of the EGCR Burning Rig. With the code appropriately adjusted to accomplish this task, confidence has been increased in the capability of the computation to predict reactor behavior.

The final phase of the Hanford work has been devoted to evaluating means for limiting the possibility or seriousness of combustion occurring in the EGCR. Part of this study has been concerned with the use of silicon carbide coatings on the graphite fuel sleeves to reduce the amount of graphite available for combustion. The other part of this study has been concerned with developing effective means of stopping the combustion should a situation ever arise when this would be necessary.

\section{SUMMARY}

With some small exceptions, the experimental program outlined above has been completed. The conditions under which the EGCR Burning Rig will ignite have been established and an analytical model has been developed which predicts these conditions. Because the Burning Rig cannot exactly duplicate the reactor situation the final prediction of the safety of the EGCR must rest on computer calculations employing the above analytical model.

No advantage in retarding combustion was found in using silicon carbide coated fuel sleeves. The negative results of these tests are due both to the particular geometry of the EGCR moderator and sleeves as well as to the fact that all sleeves tested contained imperfections in the coatings.

Chlorine has been demonstrated to be an effective agent for extinguishing graphite fires. Concentrations in air of about 1 percent have been observed to extinguish graphite fires at temperatures as high as $1000^{\circ} \mathrm{C}$.

Details of the above testing program are given in five reports. $(1-5)$

\section{OXIDATION OF IARGE BLOCKS OF GRAPHITE}

Because laboratory experiments designed to measure the oxidation rate of graphite under various conditions, e.g., at different temperatures, in the 
presence of gamma radiation, and at different oxygen pressures, are commonly conducted on relatively small pieces of graphite, it is necessary to consider how these data may be applied to the oxidation of large blocks of graphite. Graphite is a porous substance. As a result, the oxidation rate is not directly dependent on the geometric, or exterior, surface which is exposed to the oxygen, but rather upon the interior pore surface down to some effective depth below the exterior surface. This effective depth for oxidation depends upon diffusion of gas into the graphite and is a subject which has been treated in detail by previous investigators. $(6)$ If $y$ is the oxidation rate of a very small piece of graphite (that is where the access of gas to the interior of the sample is not limited by diffusion), then the oxidation rate of a massive piece of graphite under the same set of conditions is given by the relationship $(6)$

$$
\text { Rate }\left(\mathrm{cm}^{3} \text { of graphite consumed } / \mathrm{hr}\right)=0.033 \mathrm{~A}\left(\frac{{ }^{\circ} \mathrm{K}}{273}\right)^{0.38} \sqrt{\mathrm{y}}
$$

where $A$ is the geometric surface area exposed to the coolant in square centimeters, and $y$ must be expressed in fraction weight loss per hour. The constant term in Equation (1) depends to some extent on the type of graphite; experiments are now underway to improve the evaluation of this constant for EGCR graphite.

From observations on the oxidation rates of some 50 small samples of the EGCR moderator graphite, the following expression for $\mathrm{y}$ was developed.(I)

$$
\mathrm{y}\left(\mathrm{hr}^{-1}\right)=6.91 \times 10^{10} \mathrm{e}^{-25,000 /{ }^{\circ} \mathrm{K}}
$$

Investigations of the oxidation rate of graphite proposed for use in the sleeves in the EGCR (Speer 901), have shown that the rates are nearly identical, that is within experimental error of $\pm 30 \%$, with those of the EGCR moderator graphite. Thus, the above equation is also valid for the sleeve graphite. Equation (2) applies for air at one atmosphere pressure, and when used in Equation (1) closely predicts the oxidation rates observed in the Burning Rig. Near atmospheric pressure the oxidation rate was found to depend on the 0.7 power of the partial pressure of oxygen.

Another point which is important in the oxidation of graphite is the amount of prior oxidation that has occurred. Oxidation opens up the pores and increases the available surface for combustion. It has been found (1) that the rate of oxidation increases during the time that the first few percent of the carbon is being oxidized. After this initial period, the rate is not changed significantly until the graphite has been about 50 percent oxidized. This effect is illustrated in Figure l. It can be expected that the graphite in the EGCR will be slowly oxidized over a period of years by impurities in the clrculating helium. After a few percent oxidation, the higher oxidation rate should apply. Thus, in order to be conservative, the above rate equations are based on data obtained after the initial burnoff period and do not take into account the slower initial rate of oxidation. 


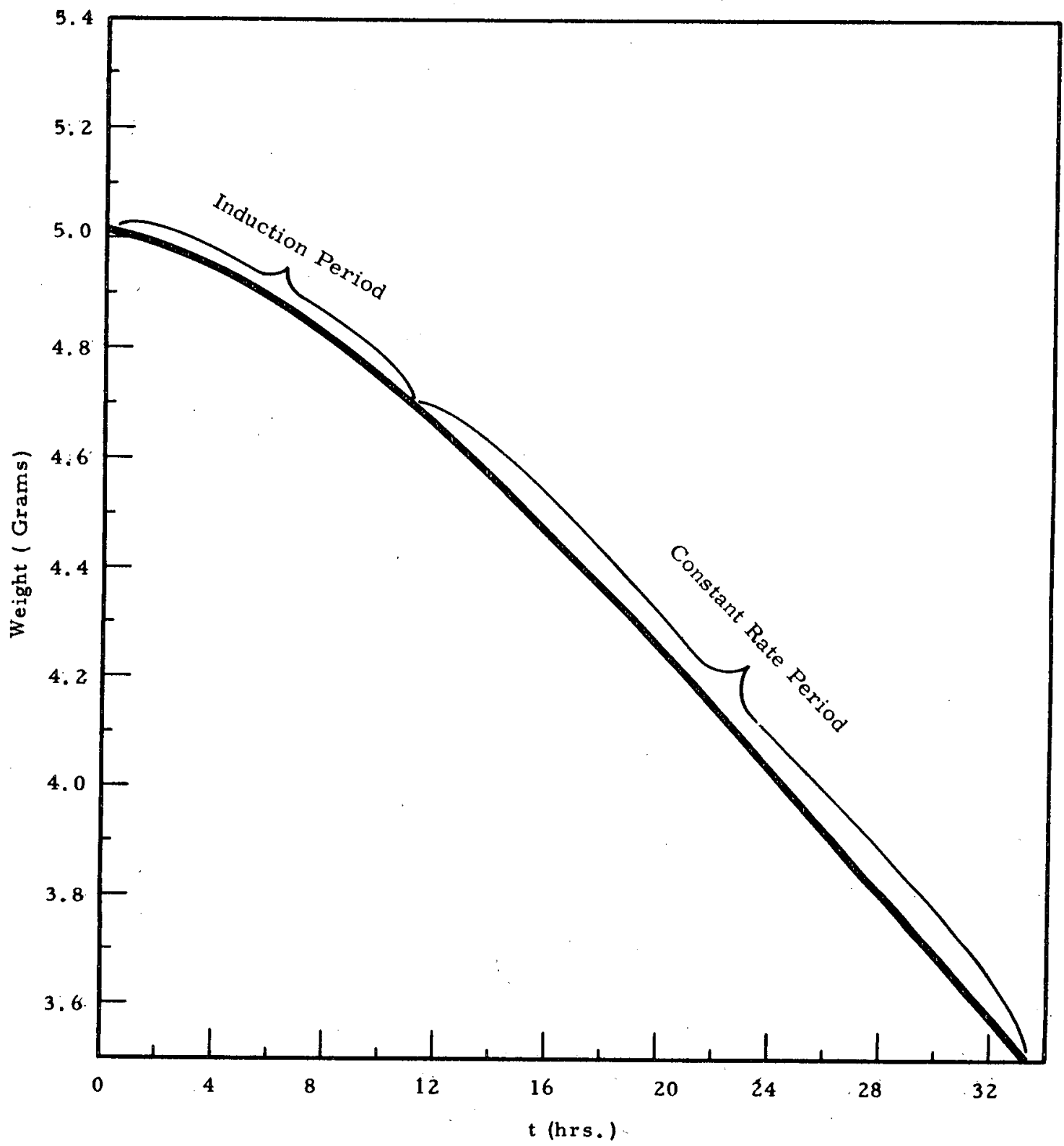

FIGURE 1

Typical Graphite Weight Loss Curve Showing the Increase in Oxidation Rate During about the First 5 Per Cent Burnoff. 


\section{EGCR BURNING RIG EXPERIMENTS}

\section{Description of Burning Rig}

Figure 2 is a cross section drawing of the Burning Rig configuration as the rig was assembled during some of the final combustion tests. A ring of EGCR moderator graphite containing four resistance heating elements is located at the outside. This outer ring simulates the moderator surrounding a single channel in the EGCR. The positioning of the four heating elements does not allow exact duplication of the temperature profile in the EGCR moderator; however, it does provide nonuniform heating patterns of the type that will occur in the reactor. In the actual reactor case, the point of maximum temperature would be moved radially outwards, thus giving a higher effective heat capacity than that obtainable in the Burning Rig. However, according to the calculations which have been made, this point of maximum temperature has no important effect on the ability of the Burning Rig to predict behavior of the EGCR.

The next feature of the Burning Rig, proceeding inwards, is the outer gas annulus where about 6.5 percent of the total coolant flow passes. In the last Burning Rig tests, it was possible to preheat this annulus air to a different temperature than the central air.

The graphite fuel element support sleeve comes next. In some tests the fuel element sleeves were coated with silicon carbide on the inner and outer surfaces. Prior to the time that sleeves were available, testing was done with a solid plug of graphite in the center containing heater rods. In a limited number of these preliminary tests the solid plug was covered with an iron pipe in order to afford only one surface, the moderator, for combustion. These early experiments are not described in detail in this sunmary report, but are outlined in Appendix II.

Inside of the fuel support sleeve is located a silicon carbide Globar heating element. This Globar element is capable of being heated to high temperatures and was used to simulate the radiant heat load from the fuel elements inmediately after shutdown. The power input to this heating element was programed to decrease with time in the same manner that the heat from the fuel elements would decrease with time.

Figure 3 shows a longitudinal section of the Burning Rig and indicates typical positioning of the thermocouples during a test. The large number of thermocouples was needed to determine. which surfaces were burning as well as to follow any change in size or location of the burning area during the progress of the combustion test. 


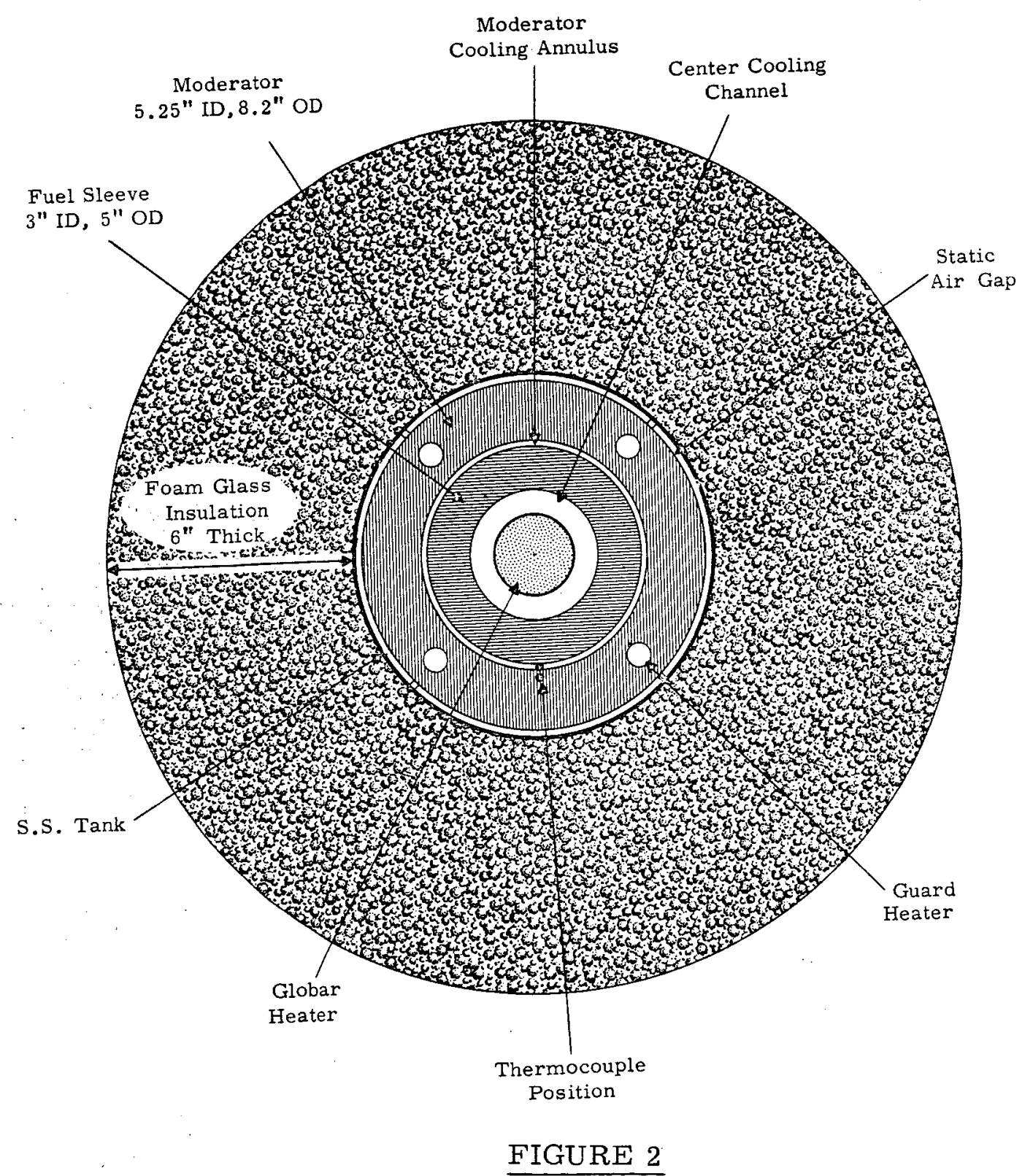

FIGURE 2

Transverse Cross Section of Burning Rig as Assembled During Tests 14 Through 18. 


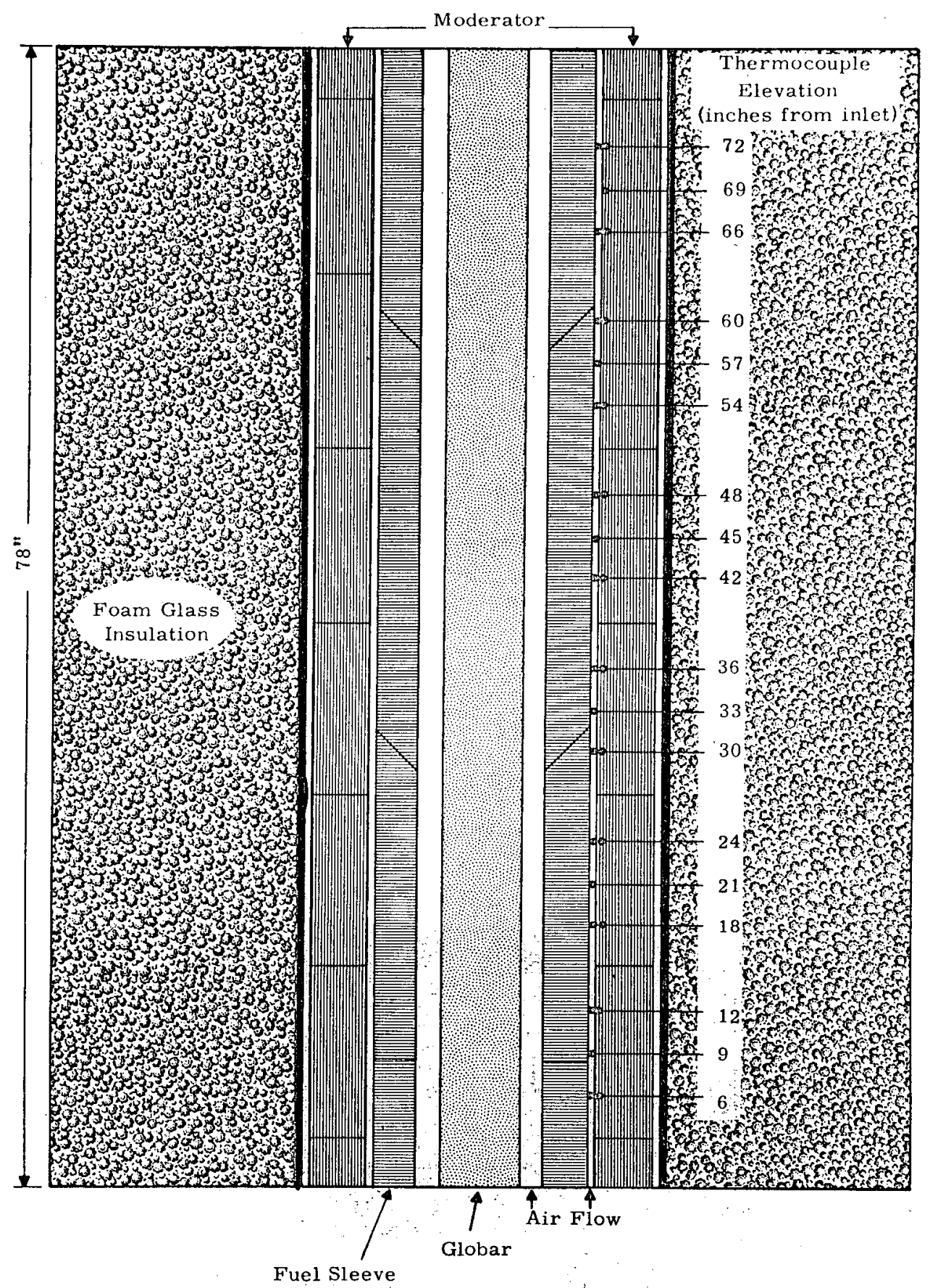

FIGURE 3 Tests 13 Through 18. 


\section{Theoretical Considerations Involving Burning Rig Behavior}

Before examining the results of the tests which were conducted in the Burning Rig, it is worthwhile to briefly consider what might be expected of this type of test. An analytical treatment, considerably more simplified than that used in transposing Burning Rig experience to predictions of reactor behavior, gives the following expression for the critical graphite temperature $\left(T_{c}\right)$. If the graphite temperature is initially above $\mathrm{T}_{c}$, the graphite will continue to heat upon the introduction of air, and if it is below $T_{c}$, it will cool.

$$
\frac{\mathrm{C}}{\mathrm{T}_{\mathrm{C}}}=\ln (\text { Rate })-\ln \left(\mathrm{T}_{\mathrm{C}}-\mathrm{T}_{\mathrm{A}}\right)+\alpha
$$

In the above equation, $\mathrm{C}$ is a constant which depends upon the activation energy for oxidation. Rate is that rate given by Equation (I). $T_{A}$ is the local air temperature, $\alpha$ is a term which depends on the available surface area as well as the heat transfer coefficients, air flow and certain other factors. In connection with the above equation, it may be noted that the critical temperature is not linearly dependent upon the oxidation rate. Furthermore, as may be implied by direct reasoning or from Equation (3); the graphite will heat up if the coolant temperature is not less than that of the graphite. Under some conditions, this latter consideration is significant because the coolant may heat up to the graphite temperature near the outlet end of the coolant passage. In these cases, other heat losses, e.g., conduction of heat through the graphite, control the critical temperature, and it is very difficult to duplicate reactor conditions in the Burning Rig.

Since it is not possible to completely duplicate reactor conditions in the Burning Rig, it also follows that the conditions under which the Burning Rig ignites are not identical with conditions causing ignition in the reactor. As an example, in early Burning Rig experiments without central cooling, i。e., a solid core replacing the fuel sleeve, self-sustained combustion was observed at graphite temperatures as low as $410^{\circ} \mathrm{C}$. In this case control of radial heat losses was very important. However, the differences between the rig and the EGCR have been taken into account by the analytical treatment, and it is believed that the extrapolation to reactor conditions can be made on a sound basis. Basically the extrapolation is performed with Equation (3), but taking into consideration the initial non-isothermal situation in the reactor and the transient conditions which would follow a coolant line rupture.

Initial Burning Rig Tests

The first Burning Rig tests (2) demonstrated that trends in behavior observed in laboratory testing also applied to situations where large blocks of graphite were being oxidized. As an example, in the laboratory testing, prior oxidation was shown to have a large effect on oxidation rate. In Figures 4 and 5 are illustrated temperature rises observed in the Burning Rig with a solid graphite core. In the experiments illustrated, the initial temperature distributions were approximately the same, but in one test (Figure 4) there was essentially no prior oxidation and in the other (Figure 5) there was a considerable amount of prior oxidation. It can be seen that the pre oxidized column showed quite rapid heating whereas the unoxidized column heated more slowly. 


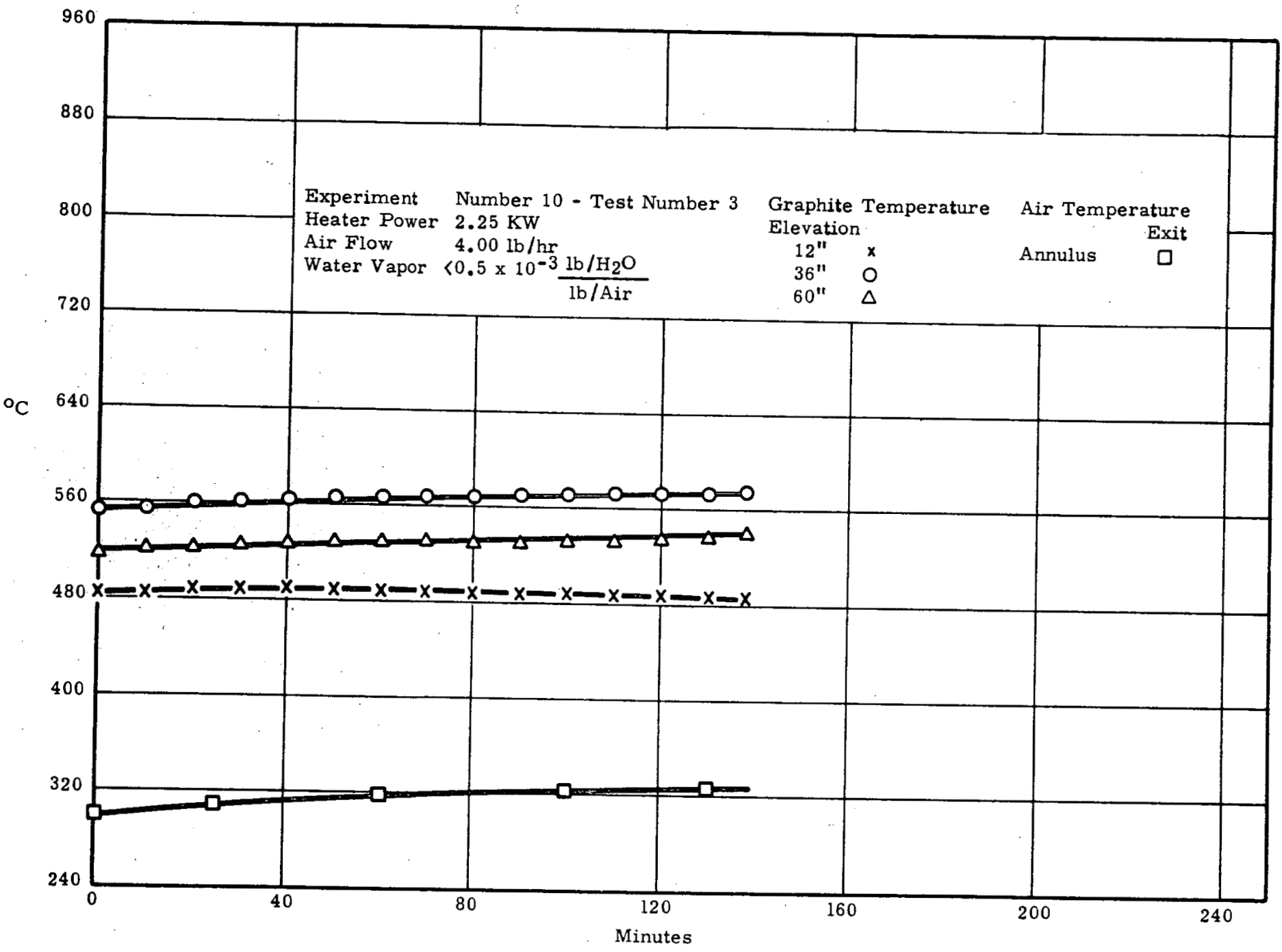

FIGURE 4

Temperature Rises in the Burning Rig During Experiment 10-3. In This Test There was Very Little Previous Oxidation of the Graphite 


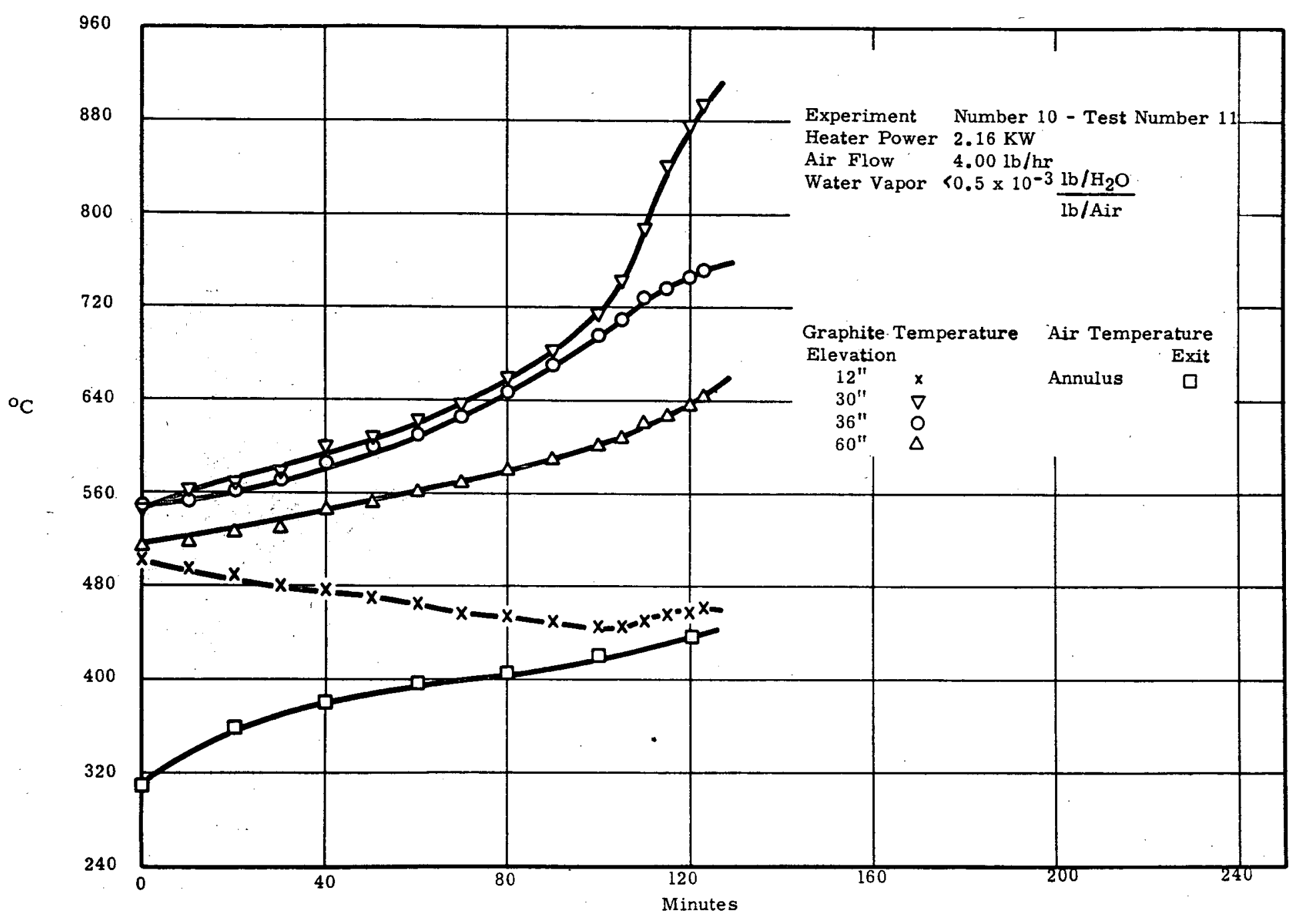

FIGURE 5 
Another important observation was that the depth of oxidation was close to that predicted by the analytical model. In Flgure 6 is shown a cross sectioned piece of graphite from the solid core in the rig. The oxidized outer surface is easily discerned and indicates the general validity of the analytical treatment in considering that the reaction occurs only to a specified depth below the graphite surface.

Additionally, it was demonstrated that it was not possible, even at maximum EGCR coolant flows, to blow out the fire in the Burning Rig once such a fire has been started. In Figure 7 the graphite temperature at the mid-plane of the colum as a function of time is shown. After combustion was initiated, the air flow was increased some 15 fold. Instead of the fire going out, it was greatly enhanced and a very rapid increase in temperature was observed. This occurred even after all electrical power to the rig has been cut off allowing considerable radial heat loss. At 120 minutes, the air flow was completely stopped allowing the fire to smother itself. However, upon reinstatement of the air flow at a later time, the fire rapidly rekindled. once a fire has started, the increased oxygen supply provided by the higher air flow more than compensates for the increase in the amount of cooling that can be provided by the extra air. This effect should be expected when there is an abundant supply of oxygen since the oxidation rate will increase exponentially with temperature, whereas the heat removal efficiency increases only approximately linearly with the graphite temperature.

\section{Maximum Credible Accident Experiments}

The final tests (3) were conducted to simulate as closely as possible the maximum credible accident conditions in the EGCR. In these tests, fuel sleeves were used as well as the central Globar heating element. Reactor air flow, inlet air temperature, moderator temperature, and after heat decay for the following accidents were duplicated.

Experiment 15-1. Moderator temperature Outer surface fuel sleeve temperature Inlet air temperature (center)

Total air flow

Experiment 15-2 Moderator temperature Outer surface fuel sleeve temperature Inlet air temperature (center)

Total air flow

Experiment 15-3 Moderator temperature

Outer surface fuel sleeve temperature Inlet air temperature (center) Total air flow $625^{\circ} \mathrm{C}$

$670^{\circ} \mathrm{C}$ $350^{\circ} \cdot \mathrm{C}$ $372 \cdot \mathrm{Ib} / \mathrm{hr}$

$590^{\circ} \mathrm{C}$ $625^{\circ} \mathrm{C}$ $450^{\circ} \mathrm{C}$ $186 \mathrm{lb} / \mathrm{hr}$

$690^{\circ} \mathrm{C}$ $720^{\circ} \mathrm{C}$ $425^{\circ} \mathrm{c}$ $287 . \mathrm{Ib} / \mathrm{hr}$

The channel cooled under every set of test conditions. 


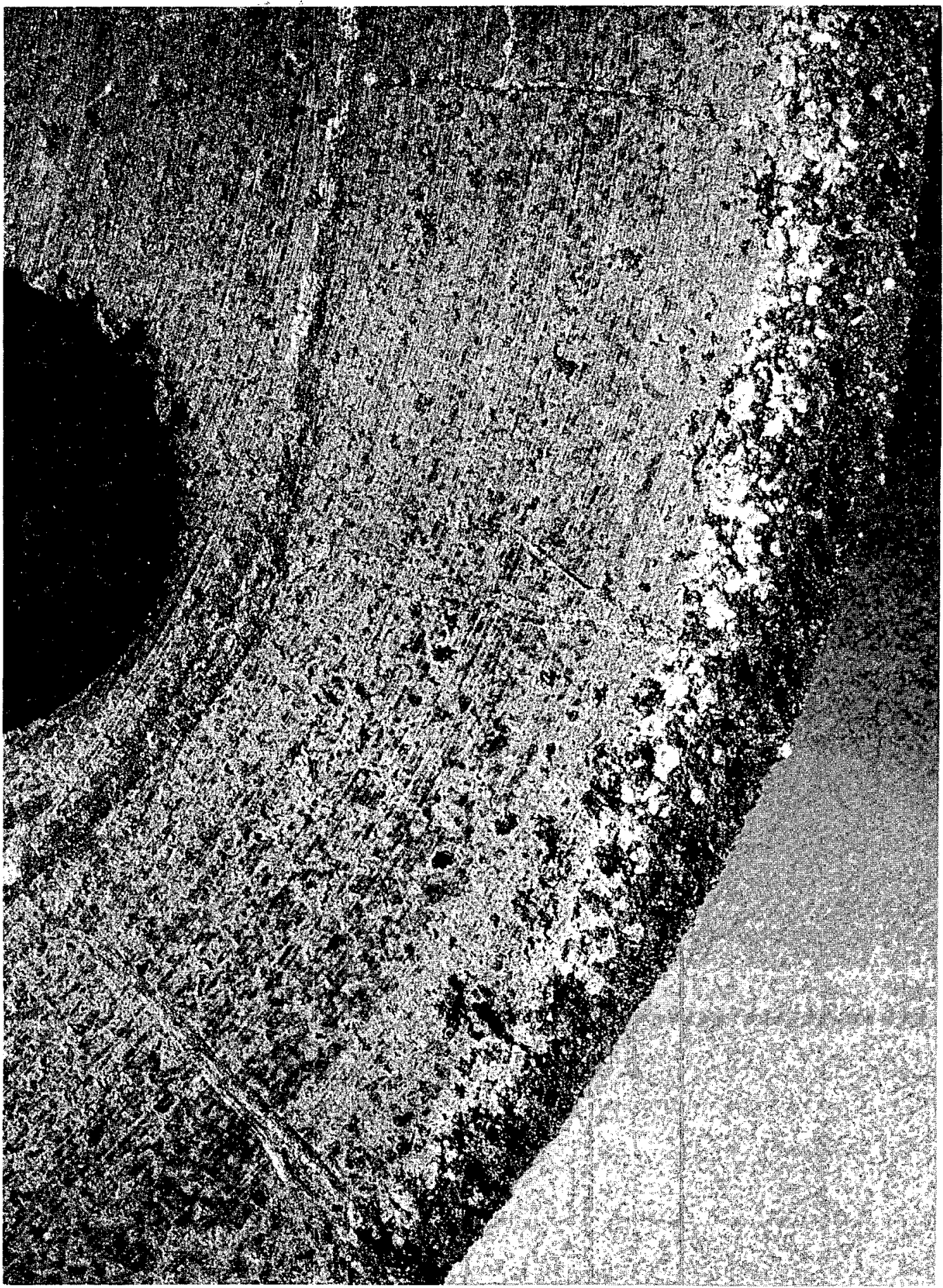

FIGURE 6

Cross Sectioned Graphite from Burning Rig。 Mag. = 5X 


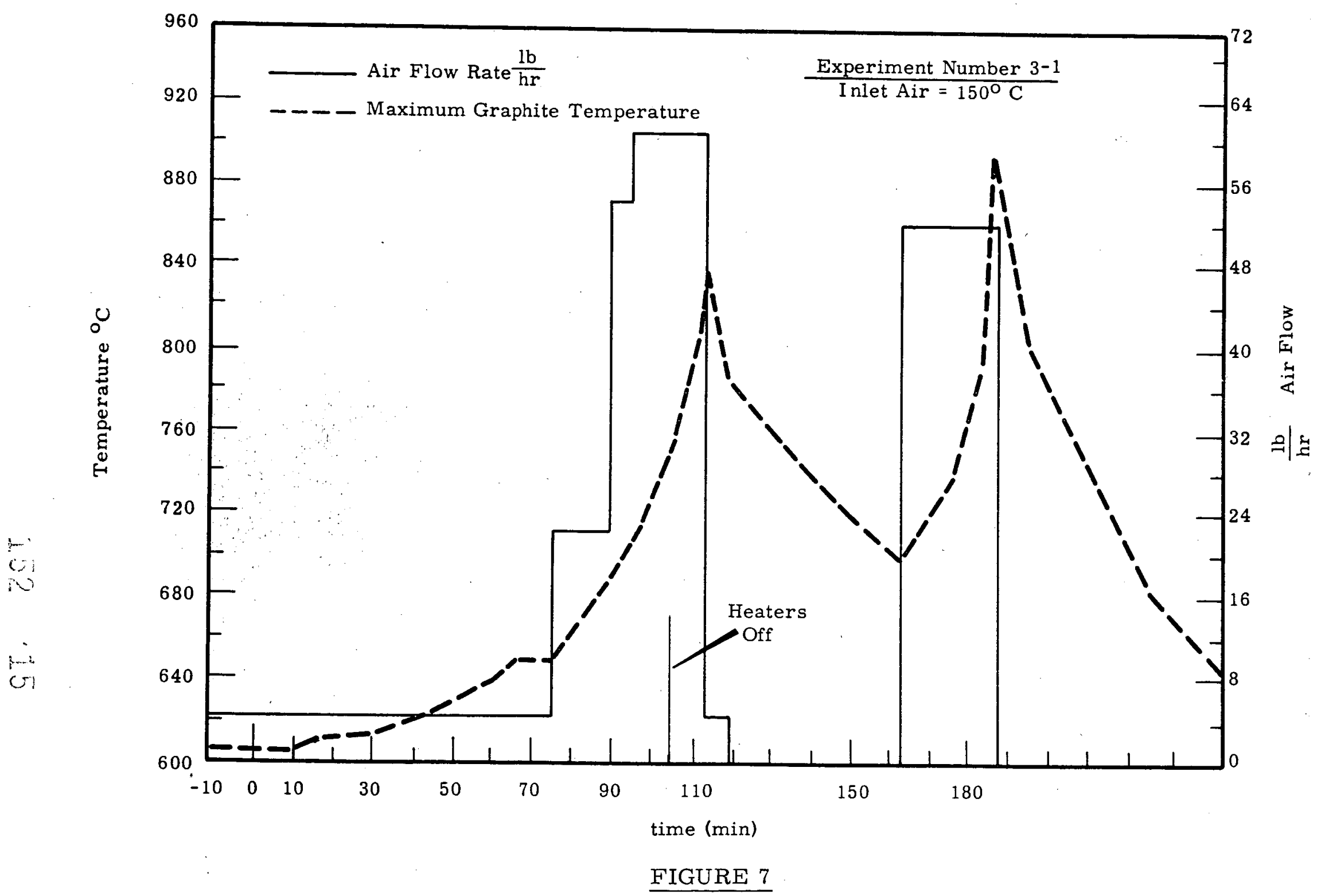

Effect on Burning Rate of Increasing Air Flow After Combustion has been Initiated. 
Further tests were run to determine conditions under which self-sustained combustion could be initiated. At a flow of $287 \mathrm{lb} / \mathrm{hr}$, combustion occurred in the assembly when the moderator temperatures were greater than $710 \mathrm{C}$ 。

The above experiments are merely an illustrative sampling of the large number of tests which were conducted with bare graphite fuel sleeves or solid central sleeves. The conditions in the tests are summarized in Appendix II, and a detailed report of the experimentation is given in References 2 and 3 .

\section{IABORATORY SCAIE EXPERIMENTS}

\section{Effects of Gamma Radiation}

It is known that under certain conditions, gamma radiation can enhance the oxidation rate of graphite with various gases. In order to investigate the importance of this effect, a series of tests were conducted $(I)$ in the presence of $a 1 \times 10^{6} \mathrm{r} / \mathrm{hr}$ gamma flux and in the temperature range of $450^{\circ}$ to $650^{\circ} \mathrm{C}$. Experiments to date have been conducted on CSF graphite (a type of purified reactor grade graphite) rather than on EGCR graphite. Figure 8 illustrates the increase in oxidation rate observed in the presence of gamma radiation. The results in Figure 8 were obtained in air at one atmosphere of pressure; similar results were obtained in pure oxygen. It is noted that the radiation enhanced reaction has a smaller dependence on temperature than the purely thermal reaction. Thus, above about $650^{\circ} \mathrm{C}$, the presence of gamma radiation is of little practical significance. From the data in Figure 8 , and from relationships between the oxidation rate of CSF and EGCR graphite, the following expression was derived for the reaction rate of EGCR graphite in the presence of ionizing radiation.

$$
\mathrm{y}=8.3 \times 10^{5} \mathrm{e}^{-14,700 /{ }^{\circ} \mathrm{K}}
$$

Experiments are in progress to determine the effect of gama flux intensity on the oxidation rate. The preliminary data indicate that the dependence on flux intensity is less than first order and additional experiments are in progress to establish the exact relationship.

\section{Effect of Prior Irradiation of Graphite}

Neutron bombardment of graphite prior to oxidation has been reported $(7)$ to increase the oxidation rate of the graphite: This effect, however, is annealable and should therefore depend upon the irradiation temperature. No data have previously been reported on samples irradjated above room temperature. Therefore, a series of samples were oxidized(I) that had been irradiated to an exposure of $10^{20} \mathrm{nvt}(\mathrm{E}>0 \mathrm{q} \mathrm{Mev})$, at temperatures of $550^{\circ} \mathrm{C}$ or higher. When oxidized, these samples showed no discernible difference in rate from those of unirradiated samples.

Tests are underway to oxidize samples which have been exposed to 20 to 30 times the dose of the above samples. No results from these tests are yet available. 
HW -71926

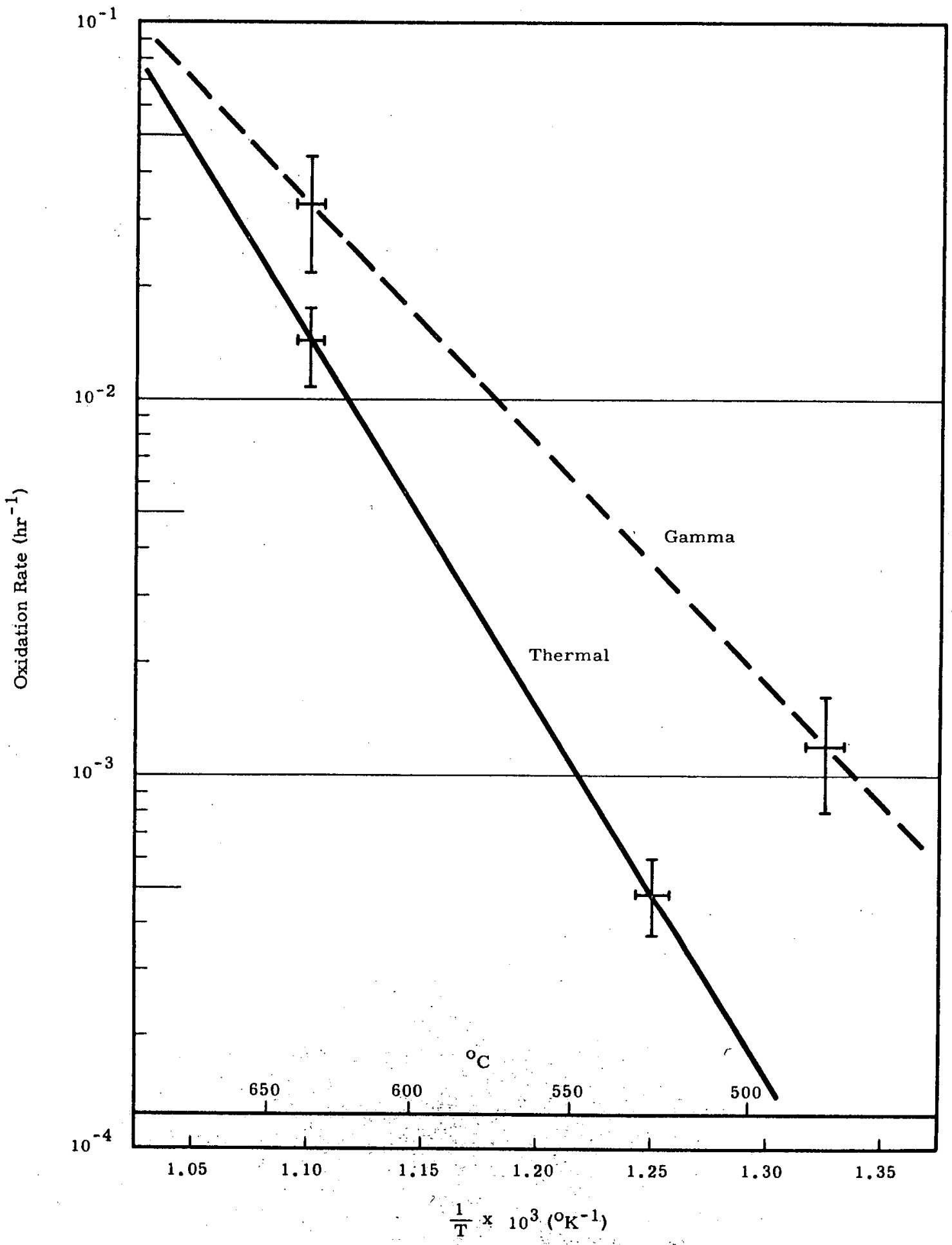

FIGURE 8

Oxidation Rate of CSF Graphite Without Radiation Present and in the Presence of $10^{6} \mathrm{r} / \mathrm{hr}$ Gamma Radiation. Tests in Air at 1 Atmosphere Pressure 


\section{Effect of Impurities on Oxidation Rate}

Metallic impurities, particularly iron and vanadium, are known to have a considerable influence on the rate of oxidation of graphite.(1) From the standpoint of oxidation, EGCR graphite is not particularly pure and oxidized EGCR graphite shows a pitted appearance which is characteristic of impurity catalysis. Figure 9 demonstrates the appearance of EGCR graphite oxidized in air at $600^{\circ} \mathrm{C}$ for 24 hours as compared with a piece of high purity graphite oxidized at the same time. The importance of conducting the oxidation tests with actual EGCR graphite, or at least a graphite equivalent in reactivity, is thus indicated. In all cases where testing was conducted with non-EGCR graphite, a correction was applied to normalize the oxidation rates to those which should be observed with EGCR graphite. The derivation of Equation (4) is an example of such a correction.

It is also possible that impurities deposited on the graphite, such as fission products or iron carried from other parts of the system, may catalyze the oxidation. No studies have been conducted on oxidation of graphite doped with fission products. However, the presence of additional impurities on the already relatively impure EGCR graphite would not be expected to have as much influence upon oxidation as in the case where these impurities were deposited on an initially very pure graphite.

Effects of Water Vapor on the Combustion Rate

Moisture has a slight catalytic effect on the oxygen mraphite reaction. Because it is possible that a steam coil rupture may occur at the same time that air is introduced into the reactor, experiments were conducted in the laboratory in which 14.5 weight percent of water was added to the air during the oxidation experiments. This is the amount of water calculated to result from a steam coil leak. Between about $550^{\circ}$ and $700^{\circ} \mathrm{C}$, this much water was found to increase the reaction rate approximately 40 percent, but this order of increase is just on the fringe of normal experimental error, and is not considered to be too significant.

Tests were also run in the Burning Rig(2) in which the moisture content of the air was varied between very dry; $i_{\circ} e_{\circ}$, less than 0.05 weight percent, to humid, i.e., approximately 1.5 weight percent moisture in the air. There was no discernible difference in the combustion behavior with the dry and the humid air. 

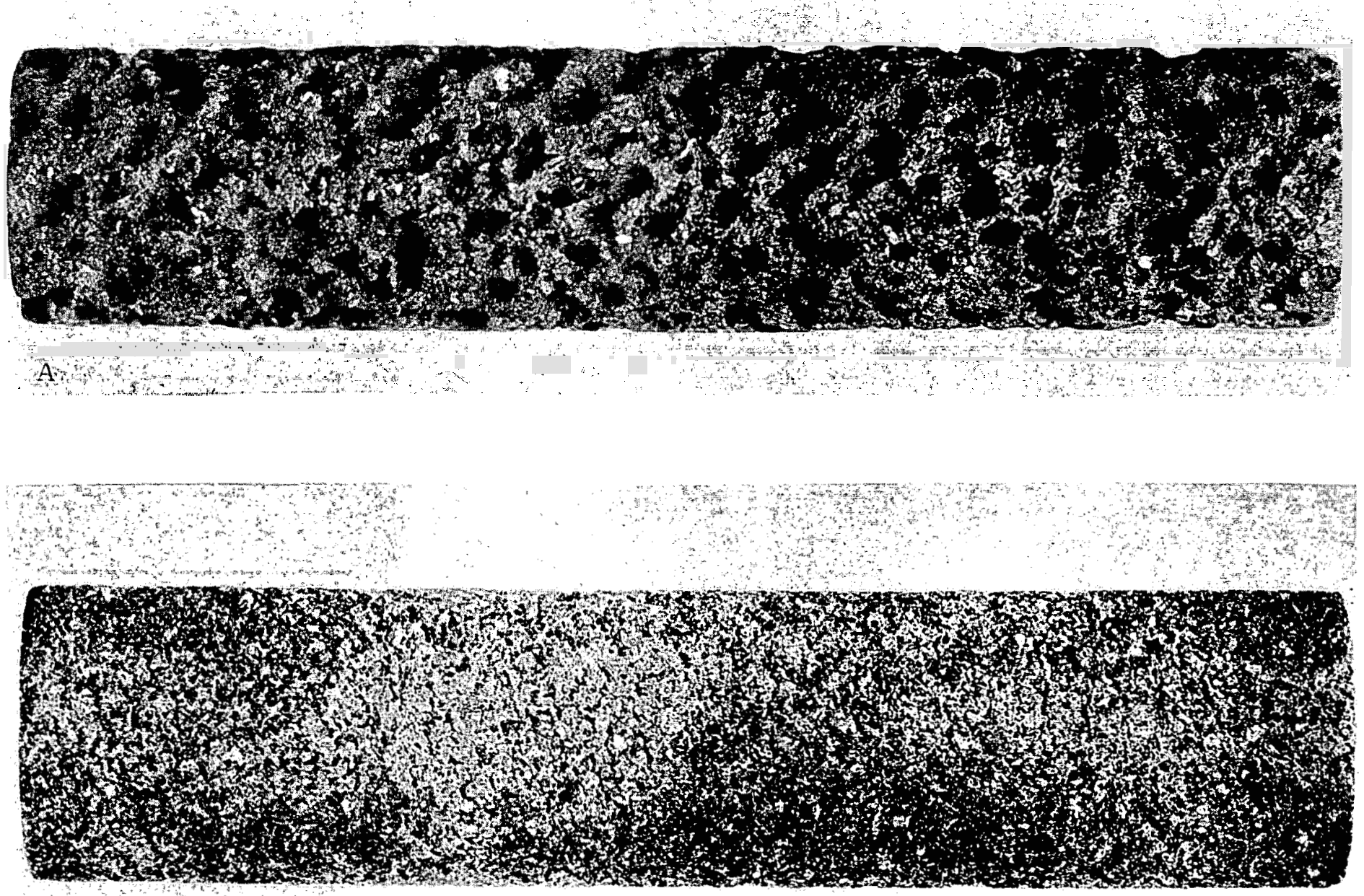

B

FIGURE 9

Comparison of Appearance of (A) EGCR and (B) Gas Purified Graphite After Oxidation in Air at $600^{\circ} \mathrm{C}$ for 24 Hours. Mag. $=4 \mathrm{X}$ 


\section{EXTRAPOIATION OF BURNING RIG AND IABORATORY TESTS TO THE EGCR CONDITIONS}

Based on the above equations for oxidation rates, computer codes have been developed by Allis-Chalmers and ORNL which predict the combustion character istics of the EGCR. These codes must, of course, take into account the heat distribution, heat transfer coefficients, and transient flow and heat generation conditions in the EGCR. Because the Burning Rig experiments duplicated the conditions in the EGCR as closely as was practical, a good test of the computer code was to check its ability to predict ignition temperatures and rates of temperature rise in the Burning Rig. A comparison of computer predictions. to Burning Rig behavior was made in the Allis-Chalmers Study IV-324。(8) Good agreement between the experimental and analytical approaches was indicated.

At this time, however, there are certain factors which must be taken into account in the computer calculations and which cannot be completely evaluated from the experiments. Thus, if a conservative calculation of combustion conditions is to be performed, the following factors should be considered in computing the oxidation rate. The first concerns the effect of gamma flux intensity。 At temperatures above $650^{\circ} \mathrm{C}$, experiments indicate that the burning rate is increased less than a factor of two by the presence of $10^{6} \mathrm{r} / \mathrm{hr}$ gamma radiation. The effect of gamma radiation at different intensities is not well defined. Since the gamma flux in reactor immediately after shutdown is probably higher than $10^{6} \mathrm{r} / \mathrm{hr}$, a correction factor for gamma radiation of a factor of three at $650^{\circ} \mathrm{C}$ should be applied to give a conservative calculation. This is believed to be an adequate correction factor, particularly since the importance of radiation rapidly decreases above $650^{\circ} \mathrm{C}$. The second point to consider is the effect of deposited impurities such as fission products on the graphite. This is a difficult consideration to correct for accurately, but such impurities would not be expected to increase the rate any more than a factor of three. The next point is the effect of water vapor due to a steam coil leak. The increase in rate of 40 percent as evidenced in laboratory experiments is believed to be adequate to cover this contingency. One last point should be mentioned; very long neutron exposures may increase the reactivity of the graphite. However, this is not regarded as likely and no correction factor for the effect is recommended. Therefore, if all the above factors are considered to be independent of temperature, the total correction to be applied to the laboratory oxidation rates is a factor of $3 \times 3 \times 1.4$ or 13. The computer calculations can treat the situation in more detail and take into account the fact that the contribution of ganma radiation decreases as the temperature increases. Experiments are now underway to narrow the uncertainty in the above factors as much as possible.

\section{INVESTIGATIONS OF THE USE OF SILICON CARBIDE COATED FUEL SLEEVES TO RETARD OXIDATION}

Silicon carbide is highly resistant towards oxidation and can be bonded to several types of graphite. To provide maximum protection to the graphite 
substrate, the silicon carbide is normally impregnated with silicon to reduce the porosity of the coating. Such a coating is called siliconized-silicon carbide.

There are three important requisites for the use of siliconized-silicon carbide coatings on graphite: (1) the graphite must have the proper porosity so the coating will bond to it, (2) the coefficients of thermal expansion of both the coating and the graphite must be similar so that the coating will not crack or spall during thermal cycling (for practical purposes, this requires that a rather isotropic grade of graphite be used), (3) the graphite must be relatively stable towards radiation-induced dimensional changes so that it will not shrink and cause the coating to crack. The last two requirements, $i . e_{.}$, isotropy and radiation stability, greatly narrow the range of graphites that can be used, but at least one comercially available, satisfactory grade of graphite has been found, speer 901 .

The majority of the Hanford work on investigating coated graphites (5) is only indirectly related to the EGCR problem, and these studies are sumarized in Appendix I. The most pertinent point of these studies is the demonstration that siliconized-silicon carbide coated graphite could most likely be used in the EGCR without any degradation of the coating quality. There is still a problem, however, of obtaining coated sleeves of initially perfect quality on a production basis.

As far as the Hanford work is concerned, the direct evaluation of coatings on EGCR fuel sleeves has been done exclusively in the Burning Rig. Preliminary experiments were directed towards determining how much the combustion would be retarded if only one combustion surface, the moderator, were exposed to the air. These tests were accomplished by replacing the solid graphite plug in the center of the column with a steel clad graphite plug; thus for these tests there was no central coolant flow. A reduction in the tendency for the Burning Rig to. Ignite was noted; results are sumarized in Appendix II. All of the Burning Rig tests which utilized a solid plug in the center of the rig rather than a fuel sleeve were severe tests inasmuch as a very important heat path was not present. That path is for the transfer of heat from the burning annulus region, through the fuel sleeve by conduction, and into the coolant in the central channel. This additional cooling is particularly important since about 94 percent of the coolant passes through the central channel.

The comparison of combustion characteristics of the reactor with coated and uncoated fuel sleeves should be made based on the Burning Rig experiments in which actual fuel sleeves were used. One of the first such tests in the Burning Rig was to duplicate several maximum credible accident conditions using silicon carbide coated sleeves. These sleeves did not have perfectly continuous coatings, but they were the best available. Some of the behavior observed below was probably modified by oxidation of the sleeves through the 
flaws in the coating. Reactor after-heat decay functions were programed as power input to the radiant heating element in the center of the fuel channel. The tests and observations were as follows:

Experiment 14-1 Initial Conditions:

Moderator temperature

Outer surface fuel sleeve temperature

Inlet air temperature (center)

Total air flow

Observations: Assembly cooled; slowest rate observed was $2^{\circ} \mathrm{C} / \mathrm{min}$

Experiment 14-2

Initial Conditions:

Moderator temperature

Outer surface fuel sleeve temperature

Inlet air temperature (center)

Total air flow

Observations: Assembly cooled; slowest rate observed was $0.5^{\circ} \mathrm{C} / \mathrm{min}$

Experiment $14-3$
Initial Conditions:

Moderator temperature

Outer surface fuel sleeve temperature

Inlet air temperature (center)

Total air flow

$$
\begin{aligned}
& 615^{\circ} \mathrm{C} \\
& 630^{\circ} \mathrm{C} \\
& 225^{\circ} \mathrm{C} \\
& 372 \text {. Ibs/hr }
\end{aligned}
$$

$615^{\circ} \mathrm{C}$

$630^{\circ} \mathrm{C}$

$425^{\circ} \mathrm{C}$

$186 . \mathrm{Ibs} / \mathrm{hr}$

Observations: Moderator temperatures at mid-plane and above rose for the first five minutes to about $720^{\circ} \mathrm{C}$, remained constant for about 20 minutes and then began to fall. The SiC coated fuel sleeves apparently did not fail since cooling of the sleeves was noted almost immediately after air was introduced.

Although each of these tests indicated a safe condition, i.e., the graphite cooled, there was no apparent advantage to the behavior of the coated sleeves over the uncoated sleeves; compare the above results with those on page 11 .

other tests were conducted $(3)$, see Appendix II, to examine the combustion characteristics of the Burning Rig with silicon carbide coated sleeves. Again, these tests did not show any obvious advantage of using the coating. Consequently a final set of tests were run to check the relative merits of coated and uncoated fuel sleeves. In these tests, there were two series of runs; the 
first with silicon carbide coated sleeves and the second with uncoated fuel sleeves. Initial conditions were repeated as closely as possible for corresponding tests in each series. Data are tabulated below.

Initial Condition

Experiment Maximum Graphite Temp ( $\left.{ }^{\circ} \mathrm{C}\right)$ Total Air Flow (Ib/hr)

Observed Rate of

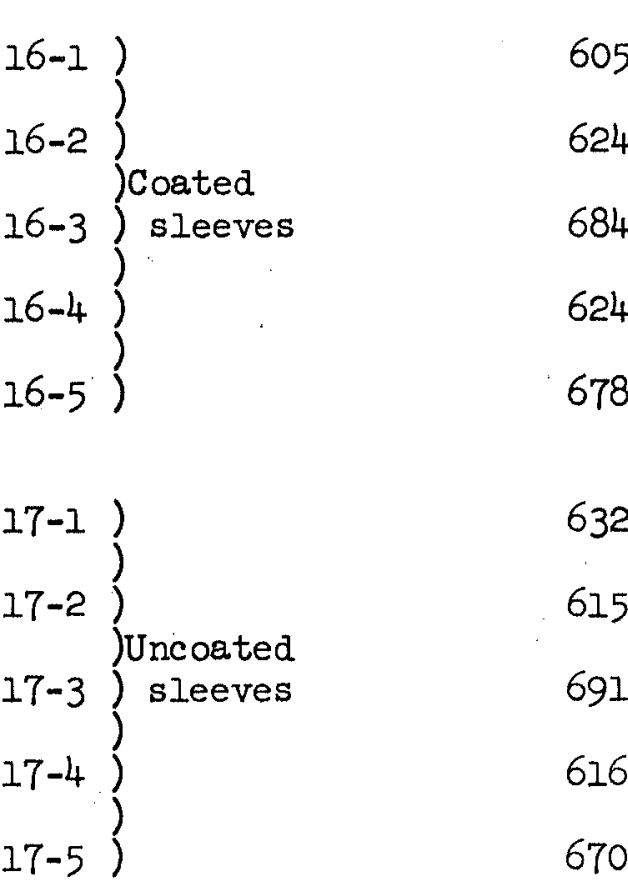

378

186

287

100

186

378

615

186

691

287

100

186 $\infty 1.7$

$-1$

Temperature Rise $\left({ }^{\circ} \mathrm{C} / \mathrm{min}\right)$

$-0.5$

$-0.05$

$+2$

$+1$

$+2$

$-11$

$+0.2$

$+0.5$

Figures 10 and 11 show the transient behavior of various temperatures that were recorded during Experiments $16-3$ and $17-3$ above. The similarity of behavior in the two cases is noted. On the basis of all the above data, there is no apparent advantage to using coated sleeves, since the Buming Rig showed no increase in stability towards combustion with coated sleeves.

In Figure 12 is a photograph of one of the silicon carbide sleeves that was used in Experiment 12 and which was rather severely damaged during combustion. The undermining of the coating originated at a defect that was present in the sleeve before testing was initiated. This indicates that any advantage which could be gained by using silicon carbide coated sleeves may be lost if the original sleeves contain small defects because the defected area will rapidly enlarge due to local burning. Imperfections in the sleeves and behavior such as illustrated probably contributed to the ineffectiveness of the sleeves in the Burning Rig tests. 


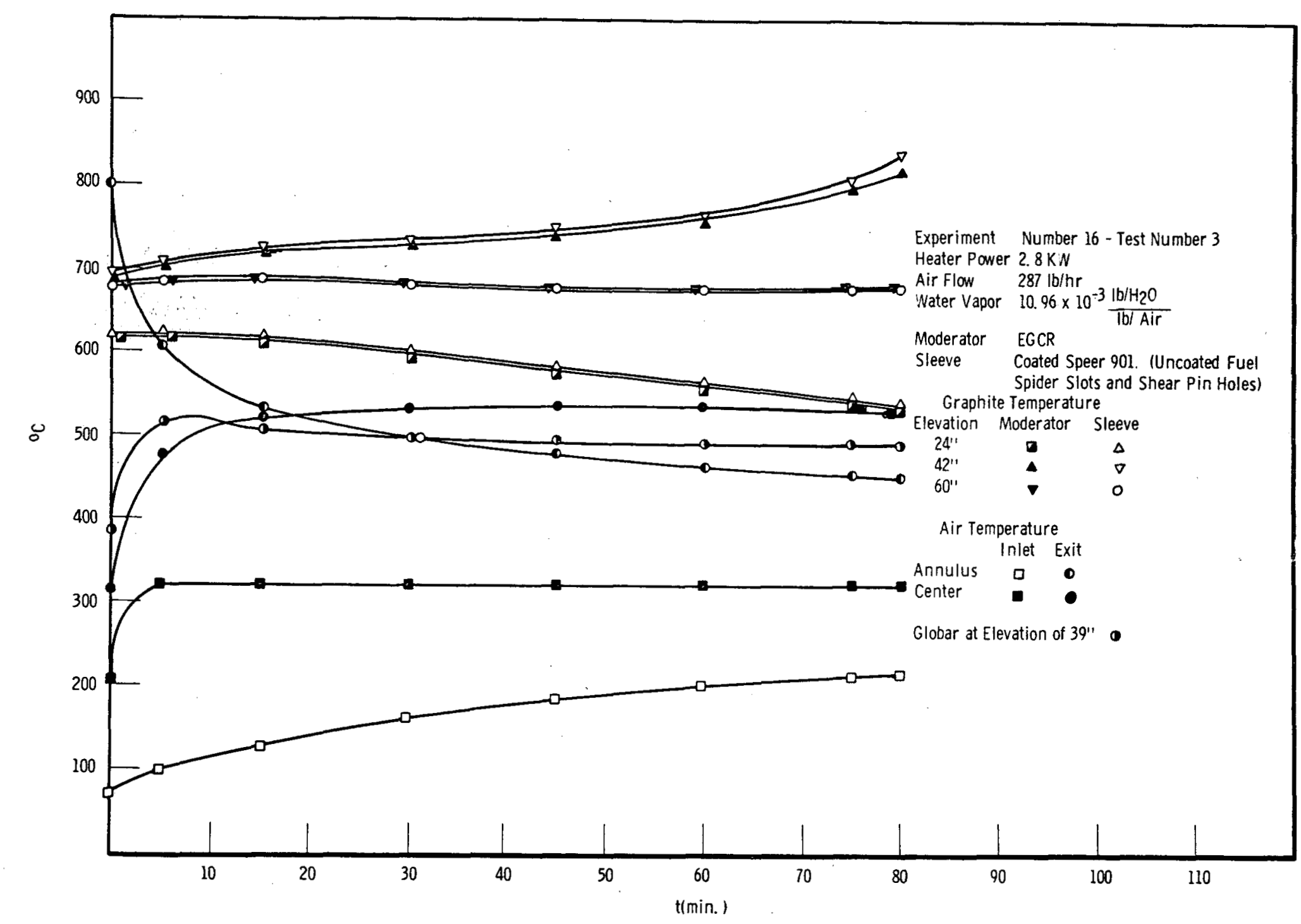

FIGURE 10

Temperature Rises in Burning Rig During Experiment 16-3. In this Experiment the Fuel Sleeves were Coated with Silicon Carbide 


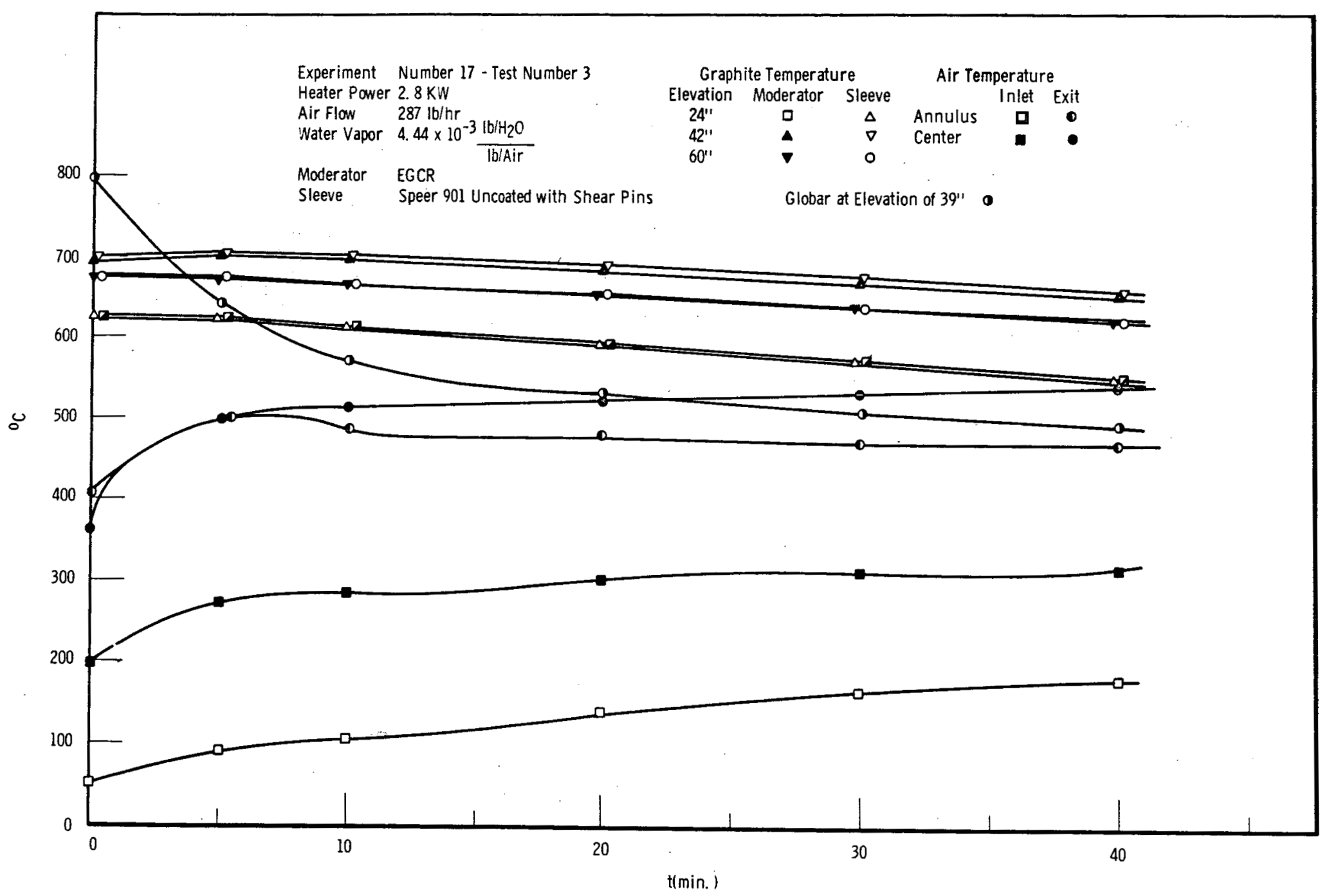

FIGURE 11

Temperature Rises in Burning Rig During Experiment 17-3. In this Experiment the Fuel Sleeves were Uncoated 

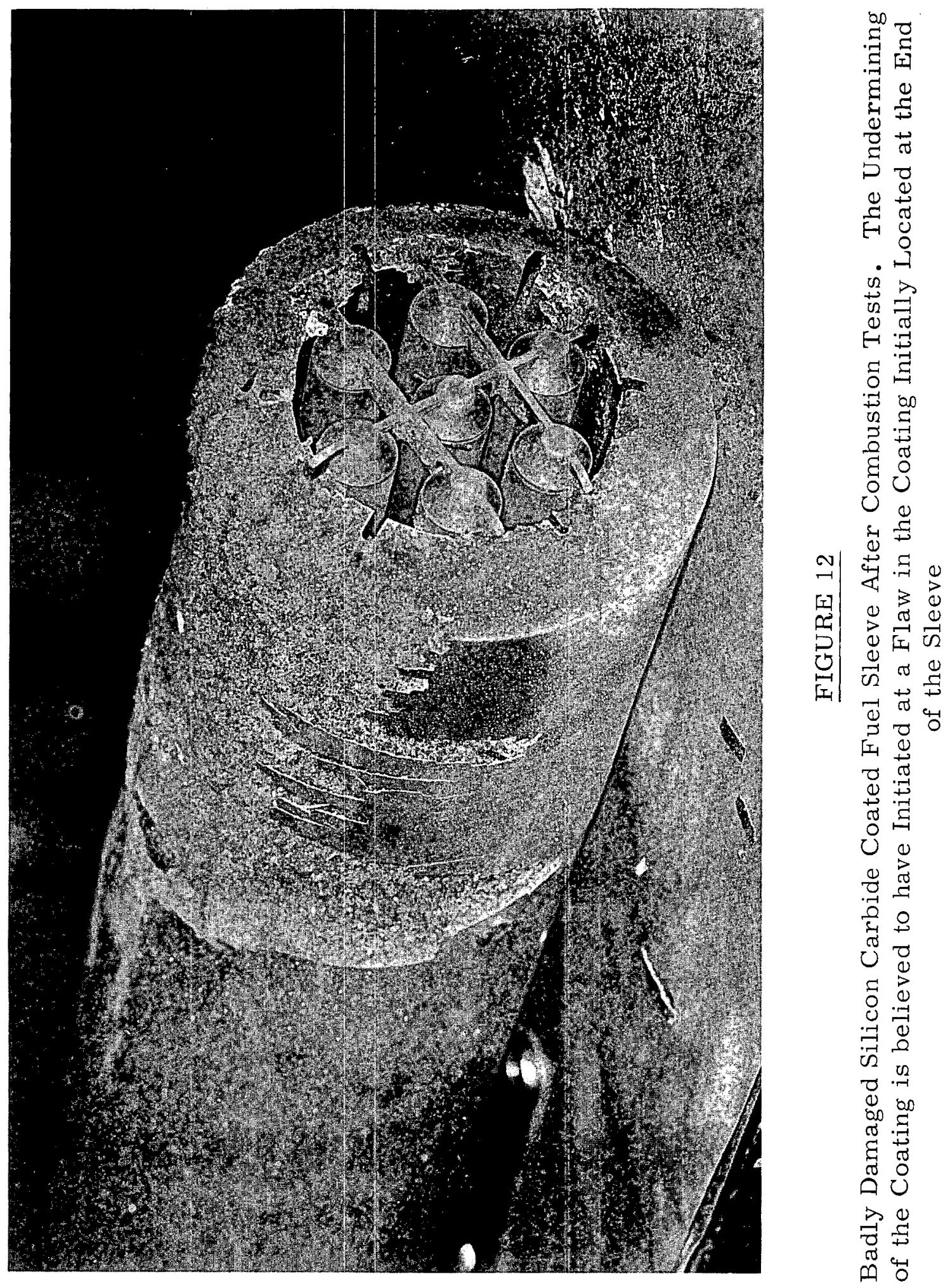


\section{EFFECT OF CHLORINE IN EXTINGUISHING GRAPHITE-OXYGEN FIRES}

Extensive laboratory testing has been conducted, (4) on the effect of chlorine in extinguishing graphite fires. It has been found that the oxidation rate in the presence of chlorine follows the rate law in Equation (5).

$$
y=\frac{k_{1}}{\left(\mathrm{Cl}_{2} / \mathrm{o}_{2}\right)^{1 / 2}+\mathrm{k}_{2}}
$$

where $k_{1}$ and $k_{2}$ are constants. In accordance with this law, the addition of the first few percent chlorine is found to drastically reduce the oxidation rate; one volume percent chlorine in oxygen cutting the rate about in half.

The effectiveness of chlorine was demonstrated on a small scale by igniting in an oxygen stream cylinders of graphite about 1 inch in diameter and then, when the fire became very rapid, introducing small amounts of chlorine. Results of such an experiment are shown in Figure 13. The rapid temperature rise after the graphite ignited is in evidence. After about 20 minutes the therma insulation surrounding the sample chamber was removed so that the burning graphite could be viewed; this action permitted some radial loss of heat so that the rate of temperature rise decreased. At about 25 minutes, approximately one percent chlorine was added, the visible flames immediately extinguished and the graphite started to cool.

It was considered important to determine whether the chlorine would also be an effective inhibitor in the presence of ionizing radiation. The primary effect of radiation is to produce active species in the oxygen, and it was not known whether these would be too reactive with graphite for the chlorine to have any significant effect in retarding the oxidation. Consequently, tests were run in which the graphite was oxidized in ozone; ozone is similar in reactivity to the species formed under irradiation. Chlorine was found to be as effective an inhibitor as in the previous tests where the chlorine was added to oxygen. In another series of tests the graphite was oxidized In the presence of a $10^{6} \mathrm{r} / \mathrm{hr}$ gamma field during the time that the chlorine was introduced. Again, the chlorine was found to have the same effectiveness in reducing the oxidation rate.

Based on the above results, it is reas onable to assume that an in-reactor fire could be extinguished by the addition of small amounts of chlorine. As an additional experiment for the EGCR case, tests are planned in which chlorine will be introduced to the Burning Rig after it is caused to ignite.

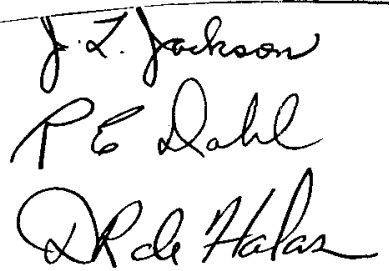

Nonmetallic Materials Development Operation Hanford Laboratories Operation

$$
102 \quad 27
$$




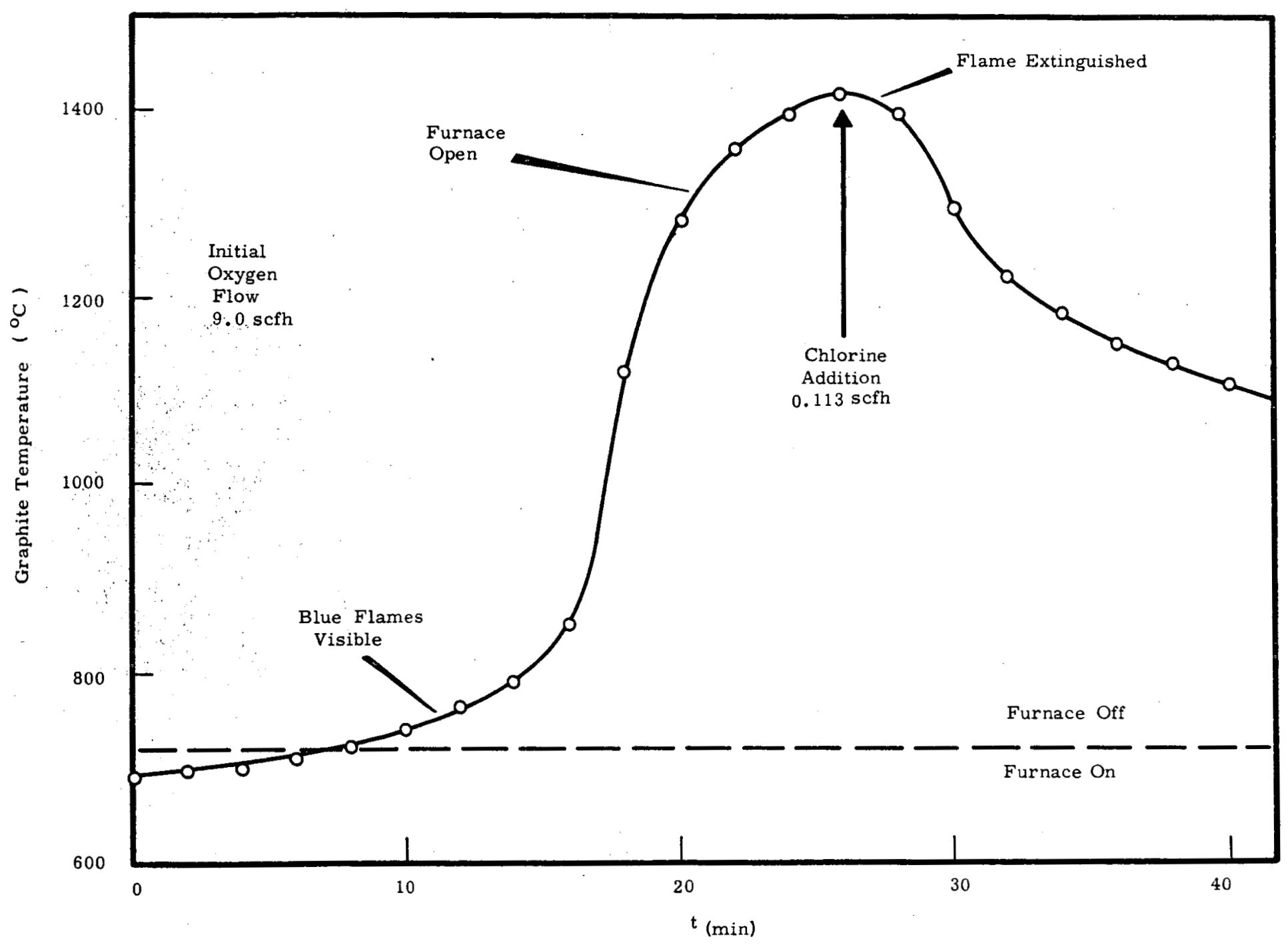

FIGURE 13

Effect of Chlorine Addition on the Combustion of a Small Piece of Graphite 


\section{APPENDIX I}

\section{SUMMARY OF WORK ON SILICONIZED-SIIICON CARBIDE COATINGS}

Continuous siliconized-silicon carbide coatings on graphite are effective protection against oxidation at temperatures over $1000^{\circ} \mathrm{C}$. If the coating is applied on an isotropic base graphite, the coefficients of thermal expansion match closely enough so that there is no degradation of the coating due to thermal cycling. The stability of the coating has been demonstrated $(5)$ by thermal cycling samples between $250^{\circ}$ and $1200^{\circ} \mathrm{C}$ in flowing air. Approximately 30 samples of different geometries; rod, balls, and prisims have been cycled along with other coated samples which had been previously irradiated. These latter samples were irradiated to an exposure of approximately $3000 \mathrm{MWD} / \mathrm{AT}$ at about $500^{\circ} \mathrm{C}$. Data from these thermal cycling tests are given below.

THERMAL CYCIE TESTING - Si-SIC COATING ON GRAPHITE

$250^{\circ} \mathrm{C}-1200^{\circ} \mathrm{C}-$ FLOWING AIR

Unirradiated Coated Graphite

Cycle Frequency Hours of wt. Change + Hours $\%$ wt. Change + Hours $\%$ wt. Change

$\begin{array}{lllllll}6 \mathrm{cyls} / \mathrm{hr} & 33 & +0.656 & 69 & +0.043 & 97 & +0.030 \\ 6 \mathrm{cyls} / \mathrm{hr} & 75 & +0.005 & 119 & +0.004 & 115 & 0 \\ 5 \mathrm{cyls} / \mathrm{hr} & 28 & +0.028 & 65 & +0.013 & 48 & +0.011 \\ 6 \mathrm{cyls} / \mathrm{hr} & 58 & +0.007 & & & & \\ 7 \mathrm{cyls} / \mathrm{hr} & 69 & +0.010 & 146 & +0.018 & 150 & +0.008\end{array}$

Irradiated Coated Graphite

Cycle Time

117 hrs

96 hrs

103 hrs
Number of Cycles

824

670

779
\% Weight Change

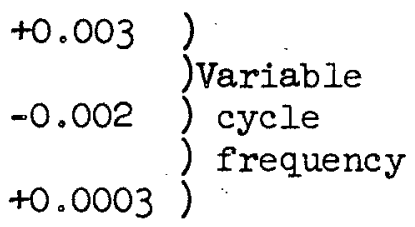


The above data were all taken on samples which are regarded as having good initial coatings on the proper types of base graphite. It is noted that under the rather severe test conditions, there were no failures of the coatings.

In addition to the thermal cycle testing, experiments were conducted in which coatings laid down on various types of graphites were irradiated. It was found that of the isotropic graphites tested Speer 901 was the only graphite, commercially available at the present time, which did not contract to a degree where the integrity of the coating was lost due to cracking. Because Speer 901 graphite has not been as well characterized under radiation as normal moderator grade graphites or the EGCR moderator graphites, irradiation testing of this graphite was conducted in the EIR. _... Samples were irradiated between $1200^{\circ}$ and $1400^{\circ} \mathrm{C}$ to EGCR equivalent exposures of about $5000 \mathrm{MWD} / \mathrm{AT}$. The results showed that the Speer 901 contracted slightly more in the direction parallel to the extrusion axis than in the transverse direction but showed considerable isotropy with the ratio of transverse to paraliel contraction being only 0.6. By way of comparison, EGCR moderator graphite irradiated simultaneously showed approximately the same contraction rate as the Speer 901 in the parallel direction. It is interesting to note that both the Speer 901 and the (National Carbon Co.) EGCR moderator graphite. are relatively

stable towards radiation-induced contraction.

In one additional test of the coatings, coated graphite samples are being prepared for irradiation to very high exposures in the ETR. This test will determine if there is any unexpected degradation of the coating after long exposures. 
APPENDIX II

SUMMARY OF BURNING RIG TESTS AND OBSERVATIONS

Inlet Air Initial Max. Graphite

Total Air Flow, Temp, ${ }^{\circ} \mathrm{C}$ Temp, ${ }^{\circ} \mathrm{C}$ Heating

Experiment $1 \mathrm{~b} / \mathrm{hr}^{*} \quad$ Annulus Center Moderator Sleeve or Core Rate, ${ }^{\circ} \mathrm{C} / \mathrm{min}$

I - Solid central core; Speer Nuclear Grade II graphite; predried air; heaters off during runs

$\begin{array}{rrrrrrr}1-1 & 4 & 20 & -- & 635 & 635 & -0.50 \\ 1-2 & 55 & 220 & -- & 650 & 650 & -0.50 \\ 1-3 & 55 & 220 & -- & 715 & 715 & +5.4 \\ 1-4 & 55 & 20 & -- & 735 & 735 & +7.3\end{array}$

2, 3, and 4 - Same, except heaters controlled to give adiabatic conditions during experiments

$\begin{array}{lcccccc}2-1 & 4.4 & 20 & - & 410 & 410 & +0.08 \\ 2-2 & 4.4 & 20 & -\infty & 440 & 440 & +0.33 \\ 2-3 & 4.4 & 20 & -\infty & 470 & 470 & +0.25 \\ 2-4 & 19.0 & 20 & -\infty & 460 & 460 & +0.17 \\ 2-5 & 19.0 & 20 & -\infty & 640 & 640 & +1.3 \\ 2-6 & 54.5 & 20 & -\infty & 680 & 680 & +3.3 \\ 3-1 & 4 \text { to } 60 & 220 & -\infty & 610 & 610 & \text { rise } \\ 4-1 & 4 \text { to } 60 & 220 & -\infty & 425 & 425 & \text { rise } \\ 4-2 & 55 & 220 & -\infty & 700 & 700 & +9.8\end{array}$

5 - New graphite assembly; solid central core; Speer Nuclear Grade II; predried air; heaters off during runs

$\begin{array}{lllllll}5-1 & 4 & 180 & -\infty & 475 & 475 & -0.16 \\ 5-2 & 4 & 170 & \infty & 530 & 530 & -0.16 \\ 5-3 & 4 & 180 & -\infty & 570 & 570 & -0.16 \\ 5-4 & 4 & 185 & -\infty & 600 & 600 & -0.16 \\ 5-5 & 4 & 200 & -\infty & 630 & 630 & -0.08\end{array}$

6,7 , and 8 - Same, except heaters controlled to give adiabatic conditions during runs
$6-1$
$6-2$
4
4
130
- 480
480
535
480
$+0.25$
140
$\infty$
535
$+0.25$ 
SUMMARY OF BURNING RIG TESTS AND OBSERVATIONS--Continued

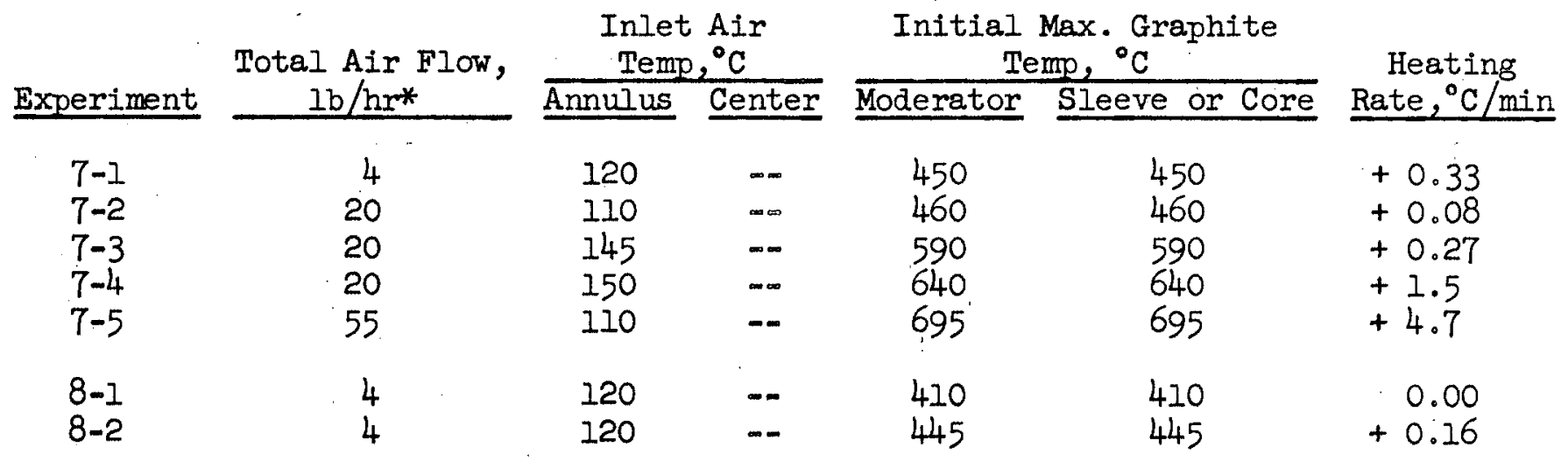

9 - Same, except heaters off during run

$9-1$

$4 \quad 120$

600

600

$-1.7$

10 - New graphite assembly; National Carbon Co. graphite; predried air except after Experiment 10-13; heaters controlled to give adiabatic conditions during runs

$\begin{array}{lrrrrrr}10-1 & 4 & 20 & -- & 450 & 450 & +0.16 \\ 10-2 & 4 & 20 & -\infty & 585 & 585 & +0.16 \\ 10-3 & 4 & 20 & -\infty & 550 & 550 & +0.16 \\ 10-4 & 4 & 20 & -\infty & 575 & 575 & +0.13 \\ 10-5 & 4 & 120 & -\infty & 525 & 525 & +0.08 \\ 10-6 & 20 & 20 & -- & 530 & 530 & +0.03 \\ 10-7 & 20 & 120 & -- & 555 & 555 & +0.42 \\ 10-7 A & 20 & 120 & -\infty & 630 & 630 & +1.1 \\ 10-8 & 4 & 20 & -\infty & 700 & 700 & +0.42 \\ 10-9 & 4 & 20 & -- & 700 & 700 & +0.50 \\ 10-10 & 12 & 20 & -- & 580 & 580 & +1.5 \\ 10-11 & 15 & 20 & -\infty & 550 & 550 & +1.4 \\ 10-12 & 4 & 20 & -\infty & 625 & 625 & +0.42 \\ 10-13 & 4 & 20 & -- & 550 & 550 & +1.0 \\ 10-13 A & 4 & 20 & -\infty & 625 & 625 & +0.92\end{array}$

Air predrier removed

$\begin{array}{lrlllll}10-14 & 4 & 20 & - & 540 & 540 & +1.3 \\ 10-15 & 4 & 20 & -- & 615 & 615 & +0.8 \\ 10-16 & 15 & 20 & -\infty & 670 & 680 & +5.0 \\ 10-17 & 15 & 20 & -- & 585 & 585 & +1.3 \\ 10-17 \mathrm{~A} & 4 & 20 & -- & 665 & 670 & +0.67 \\ 10-18 & 35 & 20 & -\infty & 600 & 600 & +2.0\end{array}$


SUMMARY OF BURNING RIG TESTS AND OBSERVATIONS--Continued

\begin{tabular}{|c|c|c|c|c|}
\hline & Total Air Flow, & $\begin{array}{l}\text { Inlet Air } \\
\text { Temp, }{ }^{\circ} \mathrm{C} \\
\end{array}$ & $\begin{array}{c}\text { Initial Max. Graphite } \\
\text { Temp, }{ }^{\circ} \mathrm{C} \\
\end{array}$ & Heating \\
\hline xperiment & $\mathrm{lb} / \mathrm{hr} *$ & Annulus Center & Moderator Sleeve or Core & Rate, ${ }^{\circ} \mathrm{C} / \min$ \\
\hline
\end{tabular}

11 - New graphite assembly; solid core enclosed in stainless steel tube;

National Carbon Co. graphite; heaters controlled to give adiabatic conditions during runs

$\begin{array}{lllllll}11-1 & 4 & 20 & -- & 600 & 600 & -0.58 \\ 11-2 & 4 & 20 & -- & 520 & 520 & +0.20 \\ 11-3 & 4 & 20 & -\infty & 565 & 565 & +0.08 \\ 11-4 & 4 & 20 & -- & 650 & 650 & +0.33 \\ 11-5 & 4 & 20 & -- & 700 & 700 & +0.42 \\ 11-6 & 4 & 20 & -- & 500 & 505 & +0.25 \\ 11-7 & 4 & 20 & -- & 560 & 565 & +0.67\end{array}$

12 - New graphite assembly; silicon carbide coated fuel sleeves containing dummy fuel elements (no central heating element); actual EGCR moderator graphite; guard heaters maintained at constant power during test (initially adiabatic conditions) except 12-4; run with power off

$\begin{array}{rrrrrrr}12-1 & 186 & 20 & 20 & 500 & 500 & -0.67 \\ 12-2 & 186 & 20 & 20 & 645 & 655 & -1.7 \\ 12-3 & 186 & 20 & 20 & 720 & 720 & +7.0 \\ 12-4 & 186 & 20 & 20 & 680 & 680 & -3.3 \\ 12-5 & 186 & 20 & 20 & 625 & 625 & -2.5 \\ 12-6 & 186 & 20 & 20 & 650 & 655 & 0 \\ 12-7 & 93 & 20 & 20 & 540 & 540 & -0.6 \\ 12-8 & 93 & 20 & 20 & 660 & 670 & +1.7 \\ 12-9 & 186 & 20 & 20 & 950 & 950 & +1.7\end{array}$

13 - New assembly; reused EGCR moderator and coated sleeves; dumy fuel elements removed; remainder of conditions same as above

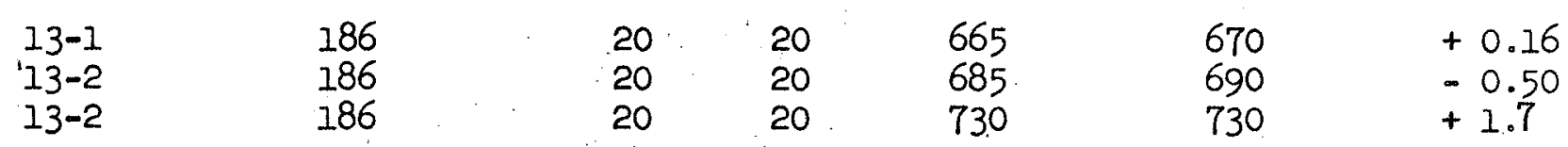

14 - New silicon carbide coated sleeves and EGCR graphite; central heating element installed and operated with programed power decay; guard heaters maintained at constant power

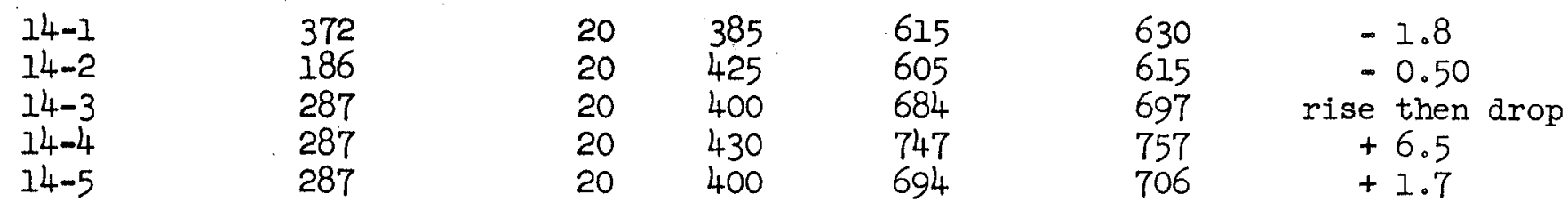


SUMMARY OF BURNING RIG TESTS AND OBSERVATIONS--Continued

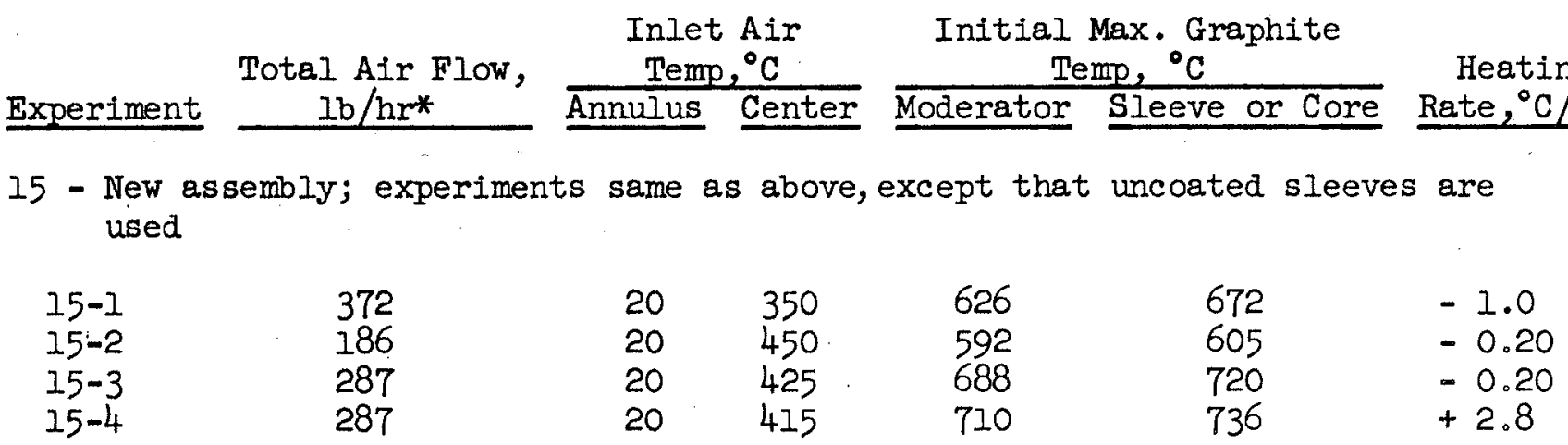

16 - New assembly; experiments same as above, except that silicon carbide coated sleeves containing slots and holes to center fuel elements were used

$\begin{array}{rrrrrrr}16-1 & 378 & 150 & 260 & 605 & 610 & -0.50 \\ 16-2 & 186 & 60 & 400 & 624 & 629 & -0.05 \\ 16-3 & 287 & 100 & 320 & 684 & 690 & +2.0 \\ 16-4 & 100 & 80 & 400 & 624 & 630 & +1.0 \\ 16-5 & 186 & 100 & 320 & 672 & 678 & +2.0\end{array}$

17 and 18 - New assembly; experiments same as above, except that uncoated sleeves were used

\begin{tabular}{|c|c|c|c|c|c|c|}
\hline $17-1$ & 378 & 100 & 410 & 632 & 636 & -1.7 \\
\hline $17-2$ & 186 & 100 & 300 & 615 & 619 & -1.0 \\
\hline $17-3$ & 287 & 100 & 300 & 691 & 697 & -1.0 \\
\hline $17-\overline{4}$ & 100 & 80 & 400 & 616 & 620 & +0.2 \\
\hline $17-5$ & 186 & 100 & 400 & 670 & 676 & +0.5 \\
\hline $18-1$ & 378 & 115 & 265 & 621 & 625 & -1.0 \\
\hline $18-2$ & 186 & 150 & 400 & 613 & 619 & +0.13 \\
\hline $18-3$ & 287 & 140 & 300 & 730 & 735 & +5.0 \\
\hline
\end{tabular}

* In each experiment where the flow was split between the annulus and central flow channel, 6.5 percent of the flow was directed up the annulus. 


\section{REFERENCES}

1. DAHL, R. E., Oxidation of Reactor Graphite Under High Temperature Reactor Conditions, $\mathrm{HW}-68493$, in yely 1961

2. DAHI, R.E., I Repoxt-Coration IOF IGGR,

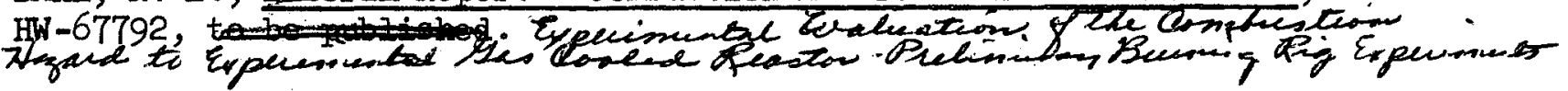

3. DAHL, R. E., Final Report - Combustion Hazard Analysis for EGCR, $\mathrm{HW}-71182$, to be published.

4. DAHL, R. E., Evaluation of Chlorine Inhibition of Graphite Oxidation as a Reactor Safeguard, HW-67255, April 1961.

5. JACKSON, J. L., The Effect of Irradiation on Siliconized-Silicon Carblde Coatings for Graphite, HW-68494, February 1961.

6. ROBINSON, P. J., The Effects of Diffusional Control of Oxidation of Graphite on the Highest Safe Temperature in Air, published in TID-7597, Book 1, March 1961 .

7. KOSIBA, W. L., and DIENES, G. J.,"The Effects of Displaced Atoms and Ionizing Radiation on the Oxidation of Graphite", Advances in Catalysis, 2, 398-405, 1957 .

8. Allis-Chalmers Menufacturing Co., Study IV-324, Graphite Oxidation Computer Model Evaluation, EGCR, July 1961. 